\title{
ARTIGOS
}

\section{ANÁLISE FISIOGRÁFICA DA BACIA DO RIO MONAPO - PROVÍNCIA DE NAMPULA - MOÇAMBIQUE}

\author{
Alécio Perini Martins ${ }^{1}$ \\ Universidade Federal de Jataí \\ Daiane Ferreira Batista ${ }^{2}$ \\ Rede particular de educação de Mato Grosso
}

João Batista Pereira Cabral ${ }^{3}$

Universidade Federal de Jataí

\section{Enviado em 23 fev. 2020 | Aceito em 21 out.2020}

Resumo: Neste artigo apresenta-se uma caracterização fisiográfica da Bacia Hidrográfica do Rio Monapo localizada na Província de Nampula - Moçambique, objetivando contribuir com a discussão sobre os sucessivos problemas com escassez de água potável na região. Os métodos e técnicas utilizados para o desenvolvimento da presente pesquisa, foram as análises empíricas realizadas em campo em novembro de 2016, levantamento fotográfico, análise morfométrica e mapeamento do meio físico utilizando geotecnologias. De acordo com os dados avaliados a bacia hidrográfica drena uma área de $8.047 \mathrm{~km}^{2}$, percorrendo o território de nove distritos de Nampula (população estimada de 1.624 .924 habitantes em 2015) em terrenos cristalinos, representados em sua maioria por gnaisses e granitos. 0 clima apresenta características semiáridas, sendo classificado como tropical seco com precipitações anuais entre $800 \mathrm{~mm}$ e $1000 \mathrm{~mm}$. A paisagem é dominada por cultivos arbóreos e florestas decíduas com características savânicas, entremeados por cultivos de man ga, caju, mandioca, milho, arroz e banana. A morfometria da bacia indica grande potencial de preservação dos recursos naturais, com baixa susceptibilidade a erosão e inundações. Considera-se que os problemas de abastecimento de água na província devem-se mais às características pluviométricas, sobretudo à concentração das precipitações de novembro a março e ao modelo de uso da terra do que às características morfométricas da bacia. É necessário que sejam adotadas medidas que favoreçam o armazenamento e a concentração de água em reservatórios artificiais, criando um sistema de regularização da drenagem aproveitando as águas precipitadas durante o verão. Palavras-chave: Análise morfométrica. Caracterização fisiográfica. Geotecnologias.

\section{PHYSIOGRAPHIC ANALYSIS OF THE WATERSHED OF MONAPO RIVER - NAMPULA PROVINCE - MOZAMBIQUE}

Abstract: The article presents a physiographic characterization of the watershed of Monapo River, located in Nampula Province Mozambique, aiming to contribute to the discussion about successive problems with potable water in the region. Regarding methods and techniques it's possible to highlight empirical analysis of the area accomplished in the field in November 2016, photographic survey, morphometric analysis and mapping of the physiography using geotechnologies. The watershed drains an area of $8.047 \mathrm{~km}^{2}$, traversing the territory of nine districts of Nampula (estimated population of 1.624 .924 inhabitants in 2015), in crystalline grounds, represented in its majority by gneisses and granites. The climate presents semi-arid characteristics, being characterized as dry tropical with annual rainfall between $800 \mathrm{~mm}$ and $1000 \mathrm{~mm}$. Arboreal crops and deciduous forests with savanna characteristics, interspersed with mango, cashew, cassava, corn, rice and banana crops, dominate the landscape. The basin's morphometry indicates great potential for preserving natural resources, with low susceptibility to erosion and flooding and a greater tendency for water to infiltrate. The water supply problems in the province are due more to rainfall characteristics, especially the concentration of rainfall from November to March and to the land use model than to the morphometric characteristics of the basin. It is necessary to adopt actions that favor the storage and concentration of water in artificial reservoirs, creating a system to regulate the drainage from the precipitated waters in the summer.

Keywords: Morphometric analysis. Physiographic characterization. Geotechnologies.

1. Doutor em Geografia. Professor Adjunto vinculado à Unidade Acadêmica Especial de Estudos Geográficos da Universidade Federal de Jataí (GO). ORCID: https://orcid.org/0000-0002-4485-0336. E-mail: alecioperini@ufg.br.

2. Doutora em Geografia. Professora da rede particular de educação do Estado de Mato Grosso. ORCID: https://orcid.org/0000-0001-8548-4021. E-mail: daiane-fb@hotmail.com.

3. Doutor em Geografia. Professor Associado vinculado à Unidade Acadêmica Especial de Estudos Geográficos da Universidade Federal de Jataí (GO). ORCID: https://orcid.org/0000-0003-2046-5975 .E-mail: jbcabral2000@yahoo.com.br. 


\section{ANÁLISIS FISIOGRÁFICA DE LA CUENCA DEL RÍO MONAPO - PROVINCIA DE NAMPULA - MOZAMBIQUE}

Resumen: El artículo presenta una caracterización fisiográfica de la cuenca del río Monapo, ubicada en la provincia de Nampula Mozambique, con el objetivo de contribuir a la discusión sobre los sucesivos problemas del agua potable en la región. En cuanto a métodos y técnicas, cabe destacar el análisis empírico del área realizado en campo en noviembre de 2016, levantamiento fotográfico, análisis morfométrico y mapeo de la fisiografía utilizando geotecnologías. La cuenca drena un área de $8.047 \mathrm{~km}^{2}$, atravesando el territorio de nueve distritos de Nampula (población estimada de 1.624.924 habitantes en 2015), en suelos cristalinos, representados en su mayoría por gneis y granitos. El clima presenta características semiáridas, caracterizándose como tropical seco con precipitaciones anuales entre $800 \mathrm{~mm}$ y 1000 mm. Los cultivos arbóreos y los bosques caducifolios con características de sabana, intercalados con cultivos de mango, marañón, mandioca, maíz, arroz y banano, dominan el paisaje. La morfometría de la cuenca indica un gran potencial de conservación de los recursos naturales, con baja susceptibilidad a la erosión e inundaciones y una mayor tendencia a la infiltración del agua. Los problemas de abastecimiento de agua en la provincia se deben más a las características de las lluvias, especialmente a la concentración de las lluvias de noviembre a marzo y al modelo de uso del suelo que a las características morfométricas de la cuenca. Es necesario adoptar acciones que favorezcan el almacenamiento y concentración de agua en reservorios artificiales, creando un sistema para regular el drenaje de las aguas precipitadas en el verano.

Palabras clave: Análisis morfométrico. Caracterización fisiográfica. Geotecnologías.

Introdução

Apesar de apresentar $77 \%$ de sua superfície coberta por água, nem todas as regiões da Terra dispõem desse recurso em quantidade e qualidade suficientes para oferecer condições de sobrevivência às comunidades e para dar suporte aos sistemas produtivos. Em uma publicação do ano de 2005 intitulada Atlas da Água, Clarke e King apontaram que 67\% da superfície terrestre apresentava fontes hídricas insuficientes, escassas ou no limite e que em 2050, 4 bilhões de pessoas viverão em países com escassez crônica de água.

Essa preocupação com a escassez hídrica está presente no meio científico desde meados do século XX, sendo tema de diversos fóruns internacionais sobre meio ambiente aos quais somaramse as discussões sobre mudanças climáticas. Desde então, muito se discute sobre a necessidade de adoção de parâmetros, modelos e unidades de estudo "ideais" para atividades de planejamento, uso e gestão dos recursos hídricos.

O primeiro passo neste longo caminho em direção à sustentabilidade do atual sistema produtivo é entender a estrutura e o funcionamento dos diversos sistemas que compõem o ambiente. Neste sentido, Bertrand (1972), fundamentado na Teoria Geral dos Sistemas de Bertalanffy (proposta em 1928), trabalha com o conceito de "sistema" para justificar que a natureza (entendida como um organismo) desempenha funções interdependentes, tanto em situações de estabilidade como de desequilíbrio. Dessa forma, impactos e medidas preventivas ou paliativas devem ser pensados como relações de causa-efeito em uma visão mais abrangente, onde qualquer alteração pontual pode vir a interferir em áreas adjacentes, transmitindo as alterações em velocidade difícil de prever ou controlar.

Adaptando a visão sistêmica às metodologias de estudo em bacias hidrográficas, os elementos de entrada seriam representados pela precipitação pluvial e seus fluxos (infiltração e escoamento), o solo e a estrutura geológica como armazenadores e condutores dos fluxos e, a saída, pelos processos de evapotranspiração e pela vazão final, perpassando por processos de transporte e uso que provocam "perdas" ou "desvios" relativos de matéria. Isso caracteriza a bacia hidrográfica como um sistema aberto, de fundamental interesse, que permite "reconhecer e estudar as inter-relações 
existentes entre os diversos elementos da paisagem e os processos que atuam na sua esculturação", representando também uma "unidade ideal de planejamento de uso das terras" (BOTELHO, 1999, p.269).

De acordo com Frei (2013), Moçambique foi um dos primeiros territórios colonizados por um país europeu e um dos últimos a se tornar independente, em 1975, apresentando diversas características econômicas ao longo dos anos. Estas fases de ocupação do território são essenciais para compreender a paisagem que se observa hoje na bacia hidrográfica do rio Monapo, distrito de Nampula, onde se desenvolveu a pesquisa apresentada neste artigo. "Durante o longo processo de colonização, as relações comerciais entre Portugal e este território colonial foram caracterizadas principalmente pela exploração e pilhagem dos recursos naturais e dos homens nativos" (FREI, 2013, p.29).

Embora o primeiro registro da chegada de Portugueses no território onde hoje se localiza Moçambique date de 1498, Bata (2014) destaca que a ocupação do território tenha iniciado por volta do século I d.C. por povos de origem Bantu, originários de regiões onde hoje se localizam Nigéria e Camarões. Estes povos cultivavam plantas, domesticavam animais e produziam instrumentos a partir da fundição do ferro. Também cavavam em busca de ouro nas proximidades dos rios, atividade que mais tarde veio a chamar a atenção de mercadores árabes na Costa Leste Africana, com destaque para as regiões de Sofala e Ilha de Moçambique, esta última compondo a foz da bacia do rio Monapo.

A partir do momento em que se torna colônia de Portugal, as diversas províncias de Moçambique passam por mais de quatro séculos de exploração de seus recursos minerais e humanos, seja pela mineração de ouro e pedras preciosas, seja pelo tráfico de escravos para outras colônias, sobretudo para o continente Americano. Esta intensa exploração é refletida no nível de desenvolvimento econômico observado em diversas vilas e aldeias percorridas em campo na bacia do rio Monapo. Após a década de 1930, Frei (2013) destaca que foram introduzidas reformas visando um maior controle do território, com destaque para o incentivo na economia agrícola para o cultivo de algodão e caju, com altas cotações no mercado mundial, colocando o país na posição de maior exportador mundial de castanha de caju, sobretudo a província de Nampula.

Considerando a grande diversidade e complexidade de ambientes encontrados na Bacia do Rio Monapo, este artigo apresentará foco na análise da paisagem com destaque ao meio físico e recursos hídricos. Localizada na província de Nampula, região Nordeste de Moçambique, a bacia do Rio Monapo apresenta $8.047 \mathrm{~km}^{2}$ de extensão (Figura 1), drenando parte do território dos distritos de Cidade de Nampula, Ilha de Moçambique, Meconta, Mecuburi, Mongincual, Monapo, Mossuril, Muecate e Nampula.

$\mathrm{Na}$ área vivem aproximadamente 1.624.924 pessoas, de acordo com estimativas realizadas para o ano de 2015 pelo Instituto Nacional de Estatística de Moçambique (INE, 2016), sendo que a maior parte das atividades produtivas estão ligadas de forma direta ou indireta às águas da bacia do Rio Monapo, como a indústria de bebidas e a mineração. Apesar de sua grande importância para a região, um dos maiores problemas registrados é a falta de água para abastecimento público, especialmente entre os meses de junho e novembro, quando o volume de chuvas diminui drasticamente e a maior parte do volume é destinada à indústria de bebidas. De acordo com o Jornal Gratuito Verdade (2017), a Cidade de Nampula, principal centro urbano da província, recebe em média 20 litros de água por dia para cada pessoa, volume muito inferior à média de países como o Brasil, onde cada morador utiliza 165,3 litros por dia (TRATA BRASIL, 2018). 
Figura 1 - Localização da Bacia do Rio Monapo - Província de Nampula - Moçambique

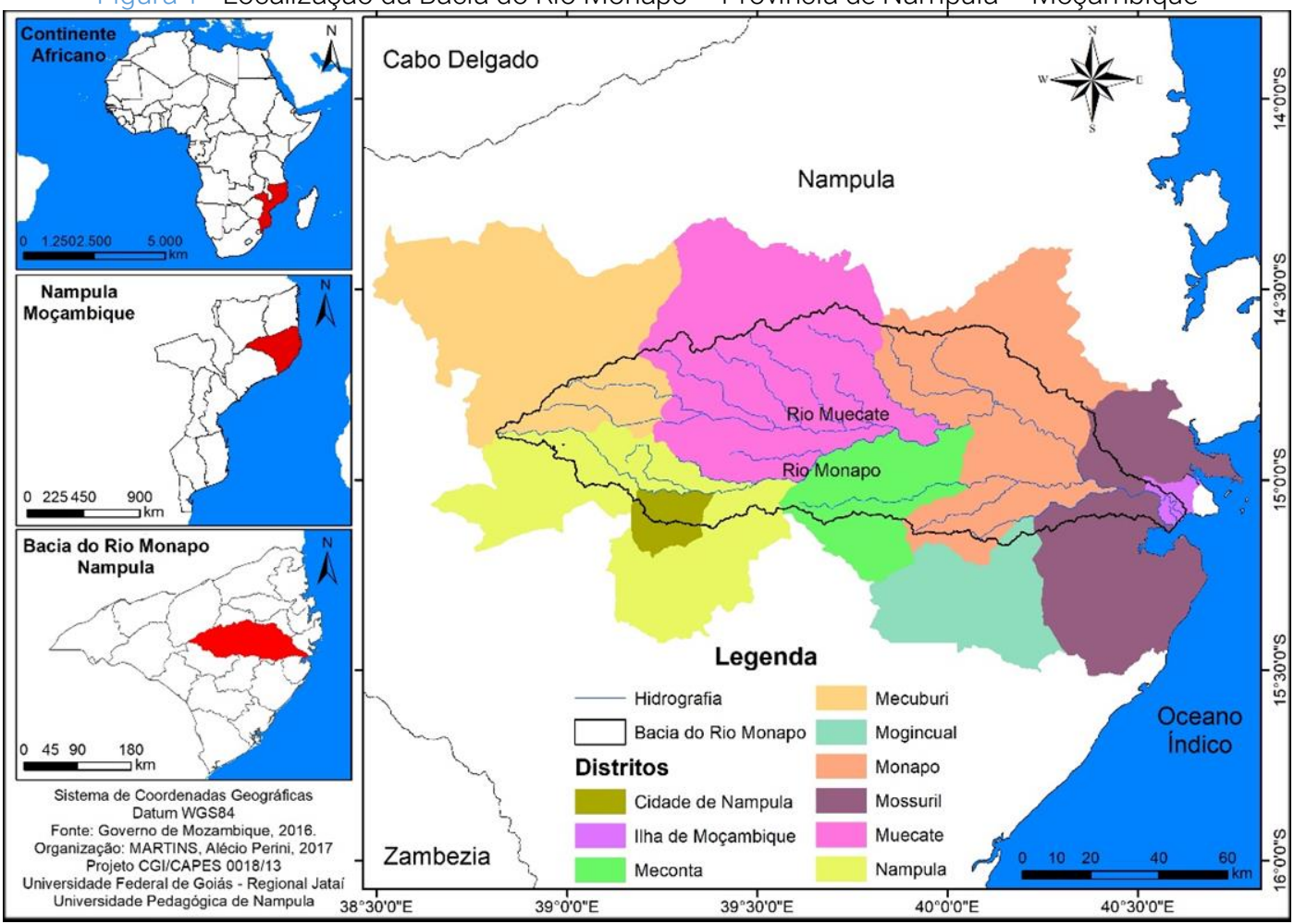

Fonte: Governo de Moçambique (2016). Organização dos Autores (2017).

O abastecimento público representa um dos problemas socioambientais mais sérios da província de Nampula. Atualmente, uma das principais demandas na região é por água potável, considerando as características da bacia e o baixo volume de chuvas anuais. Neste sentido, a pesquisa desenvolvida tem como objetivo central apresentar uma análise fisiográfica da bacia hidrográfica do rio Monapo e identificar elementos nesta paisagem que permitam compreender e indicar formas de mitigar os problemas de abastecimento público de água, a partir da utilização de geotecnologias.

Estes questionamentos surgem em atividade de campo em Nampula, Moçambique, em novembro de 2016, com apoio do Programa de Mobilidade da Associação das Universidade de Língua Portuguesa (AULP) em parceria com Coordenação de Aperfeiçoamento de Pessoal de Nível Superior (CAPES) durante a execução do projeto "Análise geoambiental do impacto da ação antrópica em bacias hidrográficas - integração ensino, pesquisa e extensão na construção de saberes entre Brasil e Moçambique.

\section{Material e Métodos}

\section{Construção do banco de dados e mapeamento da área de estudo}

Inicialmente, fez-se um reconhecimento prévio da área nos meses de setembro e outubro de 2016 a partir de imagens disponibilizadas pelo aplicativo Google Earth PRO, imagens do sensor OLI/Landsat8 e imagens de radar SRTM/NASA, ambos com resolução de $30 \mathrm{~m}$, sendo estes últimos 
obtidos no domínio Earth Explorer do Serviço Geológico dos Estados Unidos (USGS), compondo um banco de imagens da bacia do rio Monapo.

As imagens foram processadas no software ArcGIS 10.1® e, por meio das ferramentas da extensão 3D Analyst, gerou-se mapas de hipsometria, declividade, hidrografia e relevo, além dos cálculos de análise morfométrica. Como não existem muitas referências bibliográficas ou um banco de dados online com informações cartográficas do país, sobretudo da região norte, foi necessário construir uma base de trabalho que permitisse o conhecimento da área antes da realização da viagem para coleta de dados em campo.

A base para o mapa de geologia foi obtida em formato.PDF junto ao Governo de Moçambique por intermédio dos docentes da Universidade Pedagógica de Moçambique (atual Universidade Rovuma). Esta base foi transformada em figura (formato.TIF), vetorizada e redesenhada no ArcGIS $10.1 \AA$ em escala de 1:1.000.000, passando por um processo de reclassificação para agrupamento das unidades geológicas.

As bases para os mapas de solos, uso e cobertura da terra e precipitações foram obtidas junto à EMBRAPA Monitoramento por Satélite, que desenvolveu um projeto de mapeamento no território moçambicano no ano de 2012 e que, gentilmente, cedeu as informações para a conclusão da pesquisa.

As informações socioeconômicas foram obtidas junto ao Instituto Nacional de Estatística (INE, 2016) em forma de boletins e relatórios por intermédio dos professores da Universidade Pedagógica de Moçambique (UPM).

A partir destas informações, foram realizadas a análise morfométrica da bacia do rio Monapo e os mapas de localização, população residente, hidrografia, geologia, solos, precipitação anual, uso e cobertura da terra, hipsometria, declividade e relevo, que foram disponibilizados para a equipe da UPM para a composição de um atlas.

\section{Atividade de campo e análise morfométrica}

Foram analisadas 24 variáveis morfométricas, sendo 12 secundárias e 12 obtidas a partir de processamento em SIG. As variáveis secundárias, obtidas com apoio em SIG e planilha eletrônica são as classificadas como: a) Geométricas: Área (A), Perímetro (P), Número de canais de primeira ordem (N) e Comprimento axial (La); b) de Relevo: Ponto mais alto da bacia (PI), Ponto mais baixo da bacia (PII), Altitude média e Declividade da bacia; c) da Rede de Drenagem: Comprimento do Canal Principal $(\mathrm{L})$, Comprimento total dos canais (Lt), Equivalente vetorial médio em linha reta (EV) e Ordem dos cursos hídricos (HORTON, 1945; STRAHLER, 1952).

As outras 12 variáveis foram obtidas a partir dos índices secundários, também classificadas como: a) Geométricas: Coeficiente de compacidade (kc), Fator de forma (Ff), Índice de circularidade (IC), Densidade hidrográfica (Dh) e Índice de rugosidade (Ir), conforme Horton (1945), Melton (1957), Villela e Mattos (1975), Christofoletti (1980), Lopes et al. (2009), Fraga et al. (2014), Lorenzon et al. (2014), Alves et. al. (2016), entre outros; b) de Relevo: Amplitude altimétrica (Hm), Declividade do canal principal (S1), Índice de sinuosidade (IS) e Razão de relevo (Rr), conforme Strahler (1952), Schumm (1956; 1963), Lopes et al. (2009), Nardini et al. (2013), Fraga et al. (2014), Lorenzon et al. (2014), Alves et. al. (2016), entre outros; c) da Rede de Drenagem: Densidade de drenagem (Dd), Coeficiente de manutenção (Cm) e Extensão do percurso superficial (Eps), conforme Horton (1945), Strahler (1952), Schumm (1956), Lopes et al. (2009), Fraga et al. (2014), Lorenzon et al. (2014), Alves et. al. (2016), entre outros 
O processamento foi realizado por meio do software ArcGIS10.1®, licenciado para o laboratório de Geoinformação da Universidade Federal de Jataí. Como bases foram utilizadas imagens do radar SRTM/NASA disponibilizadas pelo Serviço Geológico dos Estados Unidos (USGS) com resolução de $30 \mathrm{~m}$, das quais foram obtidas todas as informações sobre hidrografia e relevo.

Após cálculos dos parâmetros morfométricos e mapeamentos temáticos prévios, foi realizada a etapa de campo, que fez parte do programa de intercâmbio de pesquisadores do projeto. A equipe permaneceu em Moçambique entre os dias 1 e 16 de novembro de 2016, período em que foram realizados palestras, minicursos, treinamentos e pesquisas de campo em colaboração com docentes e discentes da Delegação Nampula da UPM. Entre os dias 9 e 13 de novembro de 2016 foram percorridos os distritos que compõem a bacia hidrográfica do rio Monapo, de suas nascentes até o delta no oceano Índico.

A paisagem foi analisada de forma empírica, com observações sobre aspectos da geologia, solos, hidrografia, clima, uso e cobertura da terra, além das interações da população local com o ambiente. Estas análises, em conjunto com a documentação de registros fotográficos, auxiliaram na validação e correção do mapeamento de uso e cobertura da terra. Os autores coletaram pontos georreferenciados sobre a área com o uso de aparelho GNSS de navegação Garmim Etrex30 e o traçado prévio das rotas realizado com apoio de imagens do aplicativo Google Earth PRO.

\section{Resultados e discussão}

Localizada na porção nordeste de Moçambique, a bacia hidrográfica do rio Monapo constitui a principal rede de drenagem da Província de Nampula, sendo formada principalmente pelos Rios Monapo, Muecate, Messica, Amapoense e Muimite (Figura 2).

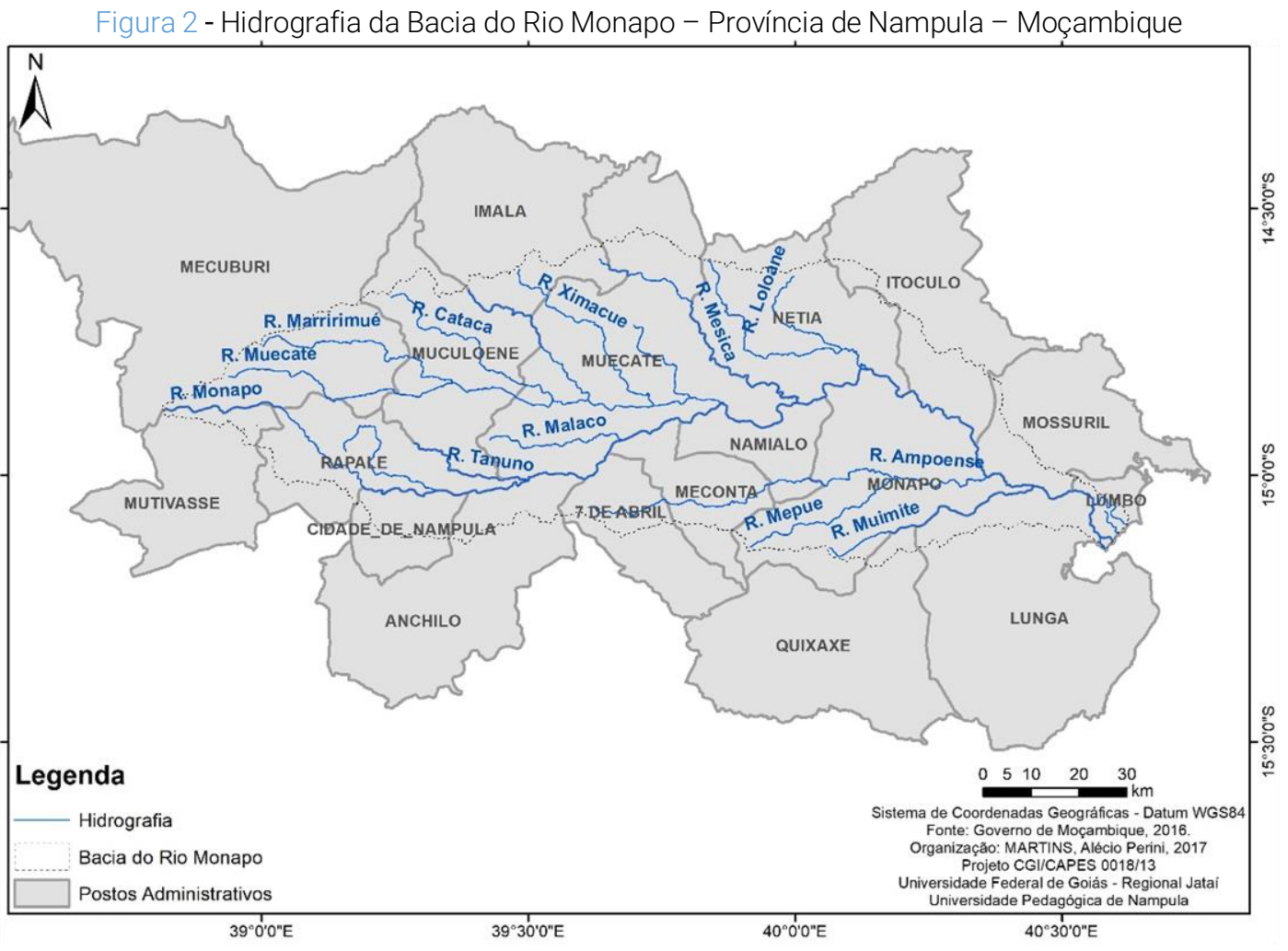

Fonte: Governo de Moçambique (2016). Organização dos Autores (2017) 
Estes cursos drenam nove distritos densamente povoados, subdivididos em 17 postos administrativos, sendo que as cidades de Nampula e Monapo apresentam mais de 300.000 habitantes (Figura 3). Com exceção da Ilha de Moçambique, todos os demais distritos apresentam populações superiores a 50.000 habitantes que residem principalmente em aldeias e vilas rurais no interior e ao longo da rodovia que liga a cidade de Nampula à Ilha de Moçambique, um dos principais destinos turísticos do país.

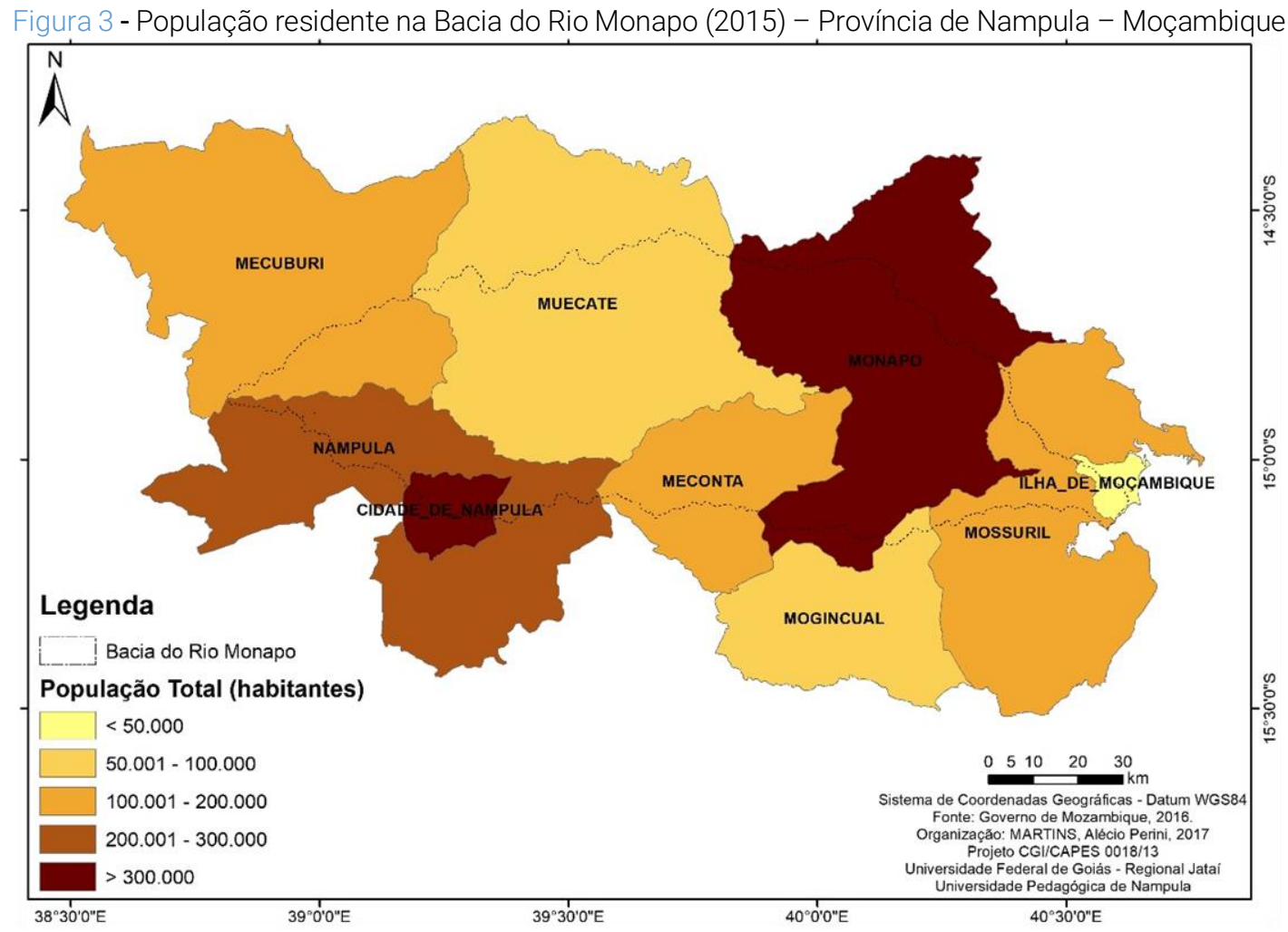

Fonte: Governo de Moçambique (2016). Organização dos Autores (2017)

A bacia encontra-se sobre terrenos compostos predominantemente por rochas ígneas e metamórficas (Figura 4). Observa-se o predomínio de diversas estruturas da Formação Nampula, composta por diferentes formações de Gnaisses como o Culicui (associado a charnoquitos), Molúcuè (gnaisses migmáticos), Mocuba (gnaisses leucocráticos) e Mamala (gnaisses tonalíticos) e, secundariamente, da Formação Monapo, compostas predominantemente por milonitos, ortognaisses, granulitos, sienitos e rochas serpentiníticas. Nas proximidades da cidade de Nampula predominam granitos da Formação Murrupula, principalmente na área de captação do reservatório que abastece a cidade (Figura 5).

No baixo curso o rio Monapo assume uma estrutura de delta no oceano Índico, onde predominam formações sedimentares mais recentes como barras fluviais, planícies de inundação e pântanos (Figura 6), além de uma pequena porção da Formação Angoche, composta por andesitos basálticos e andesitos amigdaloides. Os solos encontrados nestas áreas, classificados como 
aluvionares fluviais e lacustres, variam de arenosos a muito arenosos, com baixa capacidade de retenção de água, o que confere às formações vegetais e plantios encontrados na área um aspecto mais árido.

Figura 4 - Geologia da Bacia do Rio Monapo - Província de Nampula - Moçambique.

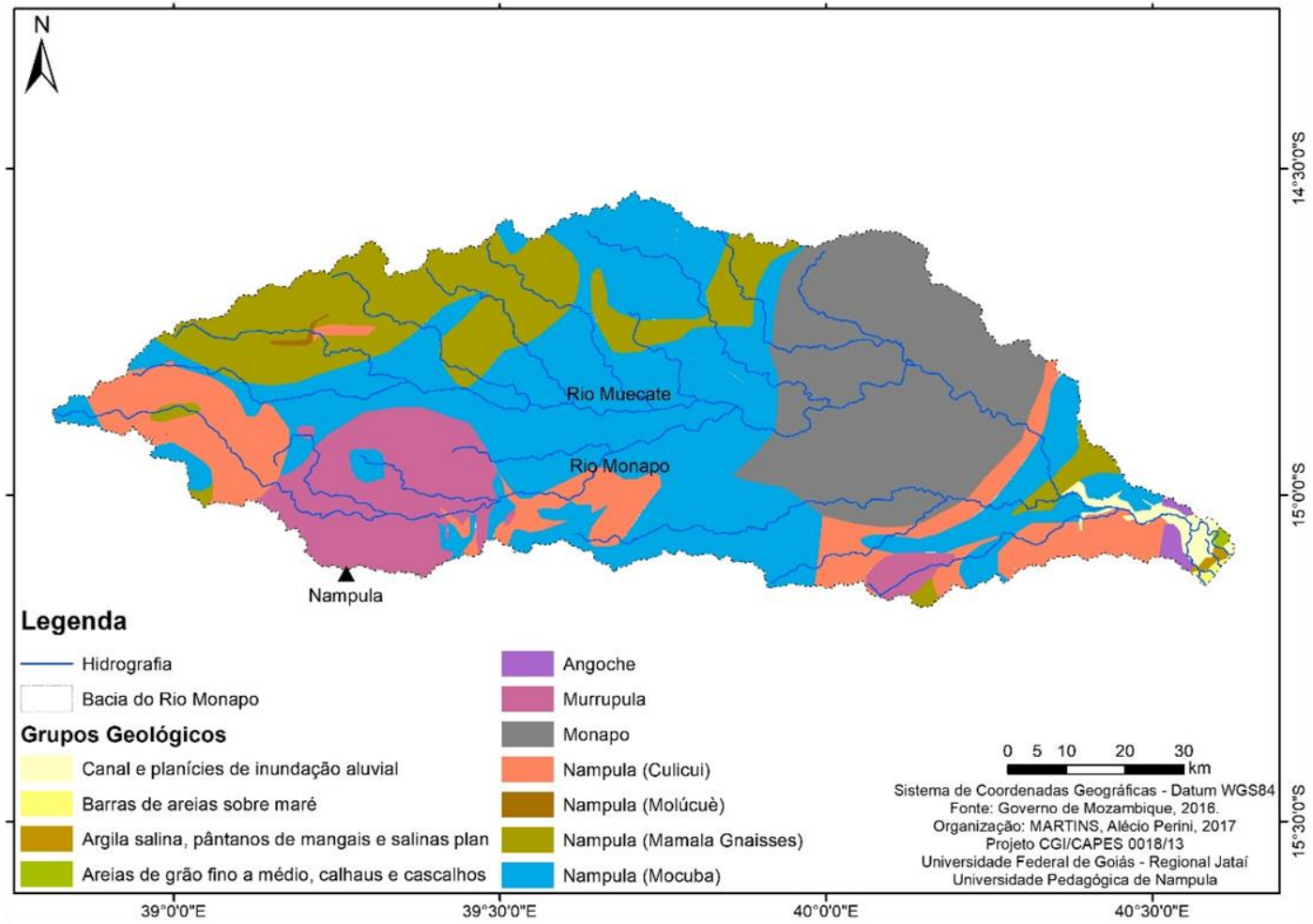

Fonte: Governo de Moçambique (2016). Organização dos Autores (2017)

Figura 5 - Morros de Granitos da Formação Murrupula nas proximidades do reservatório de captação de água para abastecimento da Cidade de Nampula Moçambique.

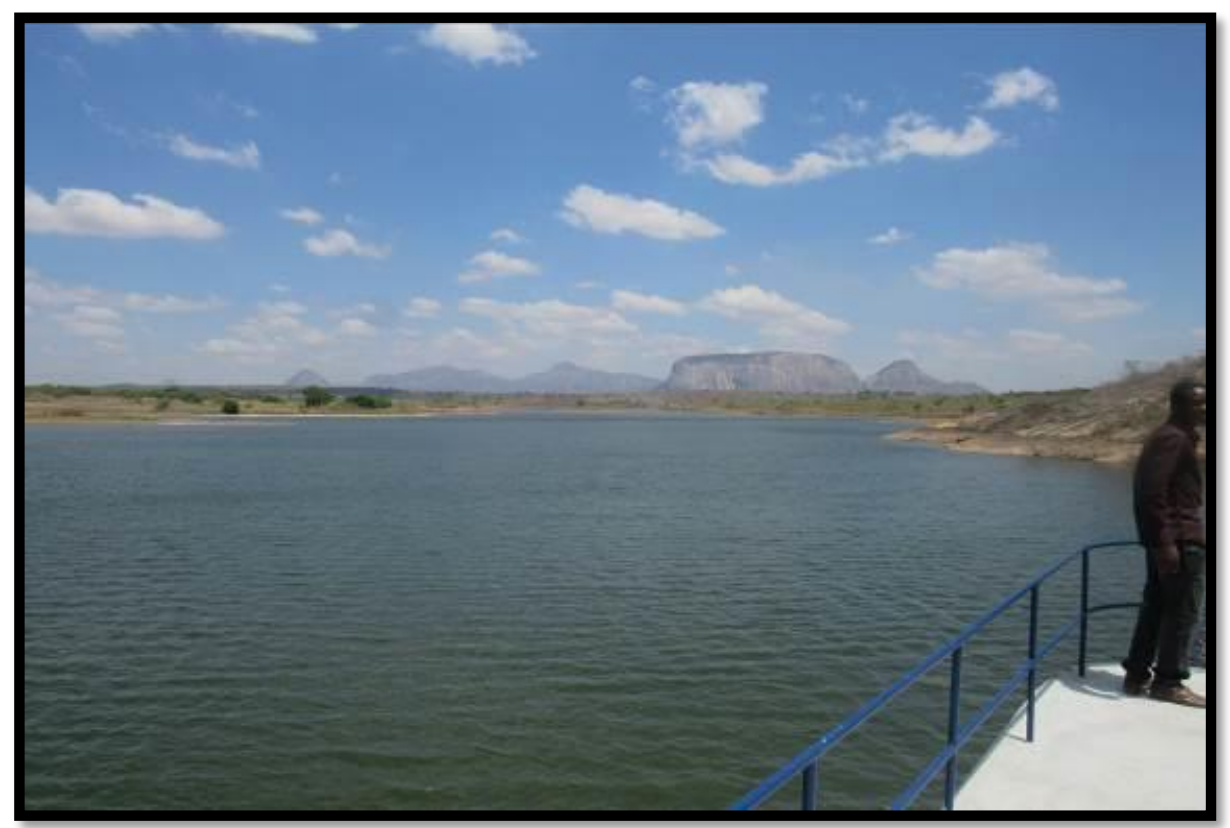

Foto: dos autores (2016) 


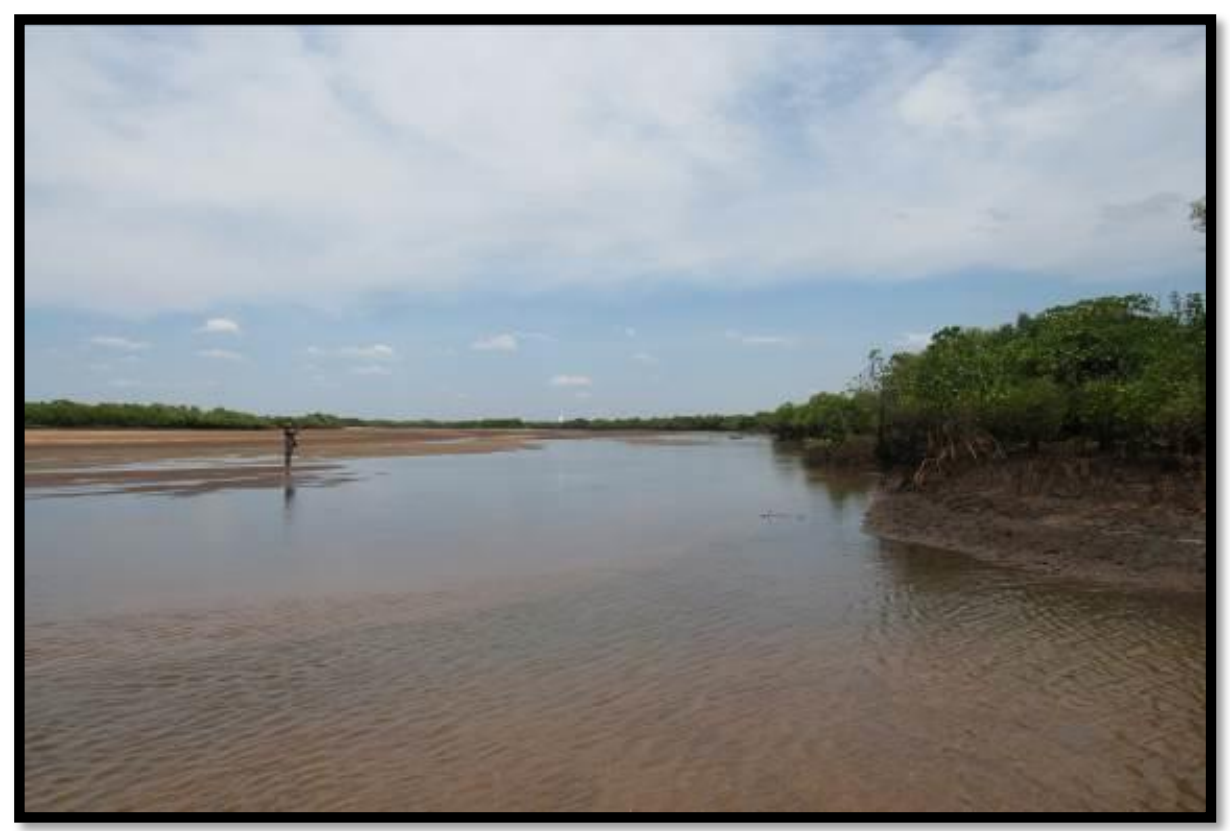

Foto: dos autores (2016)

Os solos encontrados na maior parte da bacia classificam-se como Fersiálicos crômicos e Psamo-fersiálicos crômicos (Figura 7) e carregam as características dos gnaisses e granitos que os originam. De acordo com Sertoli (2009), que estudou os solos da República de Angola, com características semelhantes aos solos de Moçambique, os solos Fersiálicos apresentam textura mais fina que o franco-arenoso e horizonte B com reserva mineral mais baixa que a de solos Eutrofersiálicos, com pouca diferenciação macroscópica acima do horizonte C.

De acordo com o relatório intitulado "Solos e potencialidades agrícolas em Moçambique: o caso da região do corredor de Nacala" elaborado pela EMBRAPA (2010), o norte de Moçambique localizase na Faixa de Empurrão do Lúrio, com uma topografia dinâmica onde alternam-se as áreas planas e afloramentos rochosos. Nas áreas drenadas pela bacia do rio Monapo, os solos Fersiálicos ocorrem associados a solos pouco desenvolvidos como os Neossolos Regolíticos, muito semelhantes aos encontrados na região semiárida brasileira. Ainda de acordo com a EMBRAPA (2010, p.13),

(...) por se tratar de uma região com características semiáridas, sabe-se que as condições de clima e de solos restringem as opções de culturas que podem produzir de forma econômica (sem irrigação) e, também, condicionam riscos de salinização, para cultivos irrigados, dependendo do manejo do solo e da água. 
Figura 7 - Solos da Bacia do Rio Monapo - Província de Nampula - Moçambique.

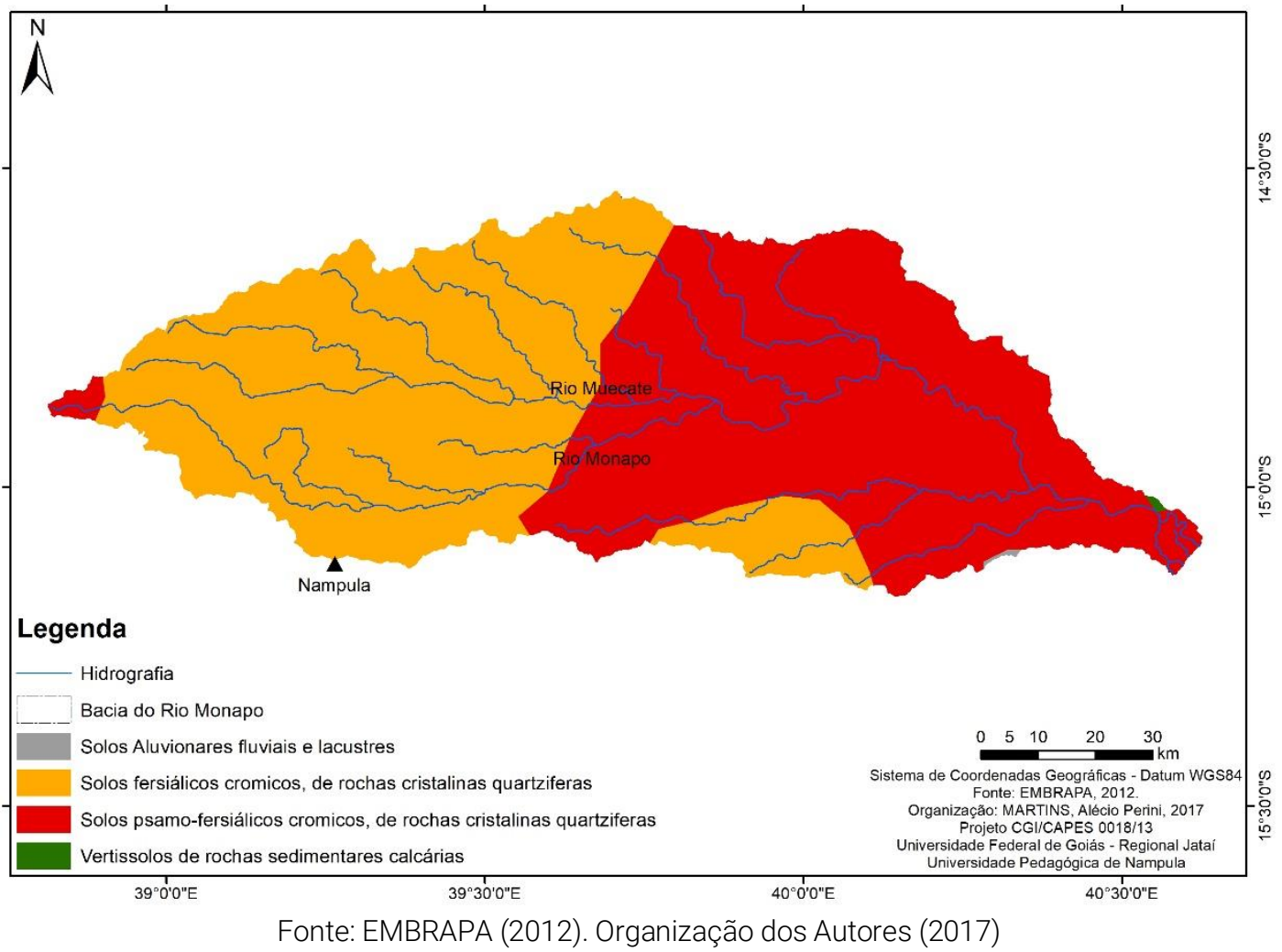

Por apresentarem altos teores de areia e silte, estes solos apresentam baixa capacidade de campo para o armazenamento de água devido à alta porosidade. Dessa forma, compreende-se, em parte, a característica intermitente da maioria dos cursos hídricos da bacia e os repetidos episódios de escassez hídrica enfrentados. Outra característica marcante dos solos é a profundidade, que raramente é superior a $100 \mathrm{~cm}$ nas áreas de contato com as formações rochosas e com declividades superiores a $8 \%$ (Figura 8).

O relevo da bacia é predominantemente plano com baixa declividade (Figura 8), indicando se tratar de um terreno muito antigo, com baixa atuação de processos morfogenéticos. Consequentemente, os rios que compõem a bacia apresentam um baixo potencial de carreamento de sedimentos, explicando a grande quantidade de bancos de areia observados nos cursos de água perenes, assim como no delta do rio Monapo. A topografia é responsável, também, pela ausência de potencial energético nestes cursos d'água.

Apesar do local mais elevado da bacia apresentar altitude de $1.060 \mathrm{~m}$, referente a um conjunto de blocos de granito chamados regionalmente de "montanhas", as nascentes dos rios Monapo e Muecate encontram-se em cotas altimétricas entre 500 m e 600 m (Figura 9), apresentando hipsometria com cotas bem definidas. 
Figura 8 - Declividade da Bacia do Rio Monapo - Província de Nampula - Moçambique

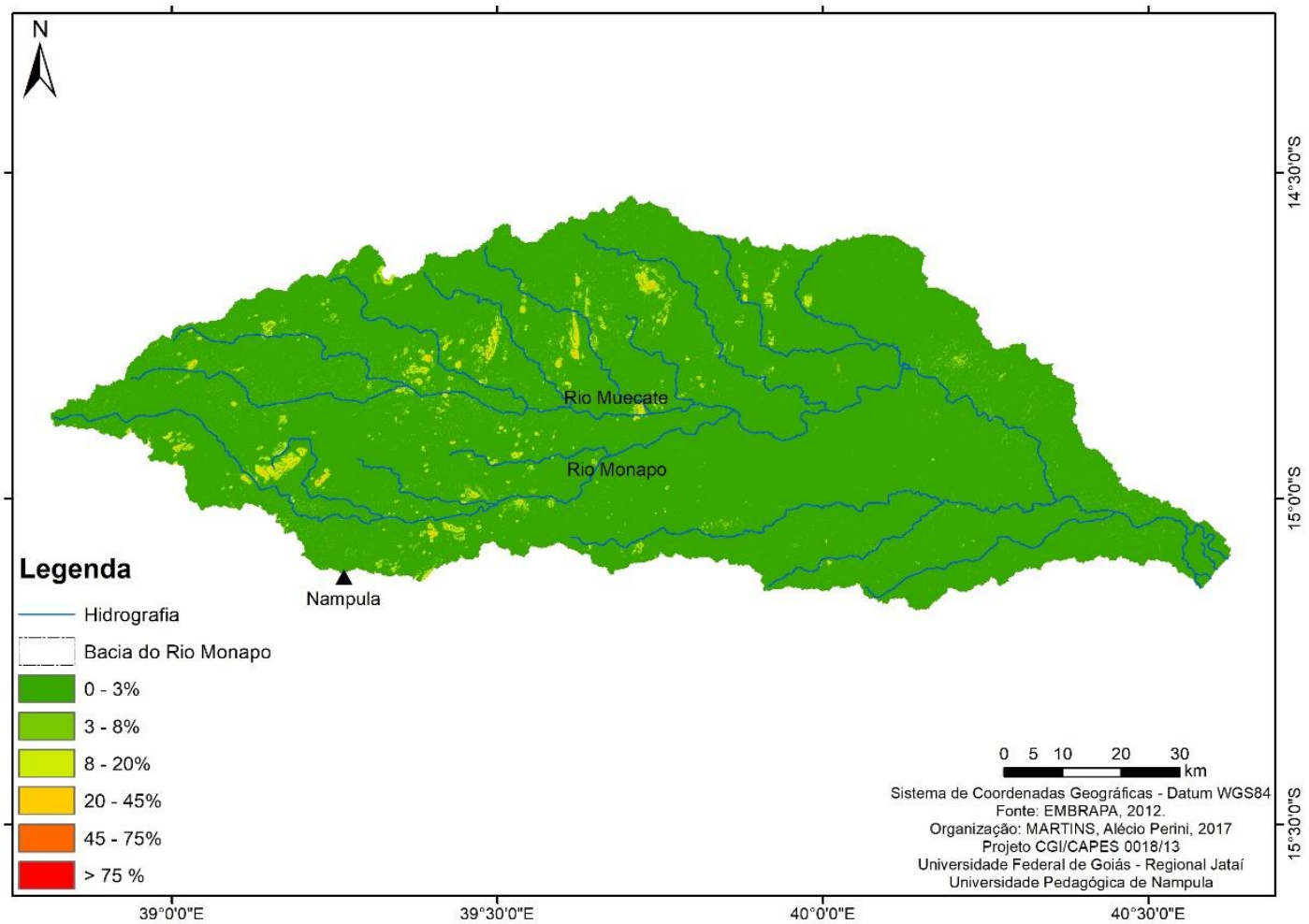

Fonte: EMBRAPA (2012). Organização dos Autores (2017)

Figura 9 - Hipsometria da Bacia do Rio Monapo - Província de Nampula - Moçambique

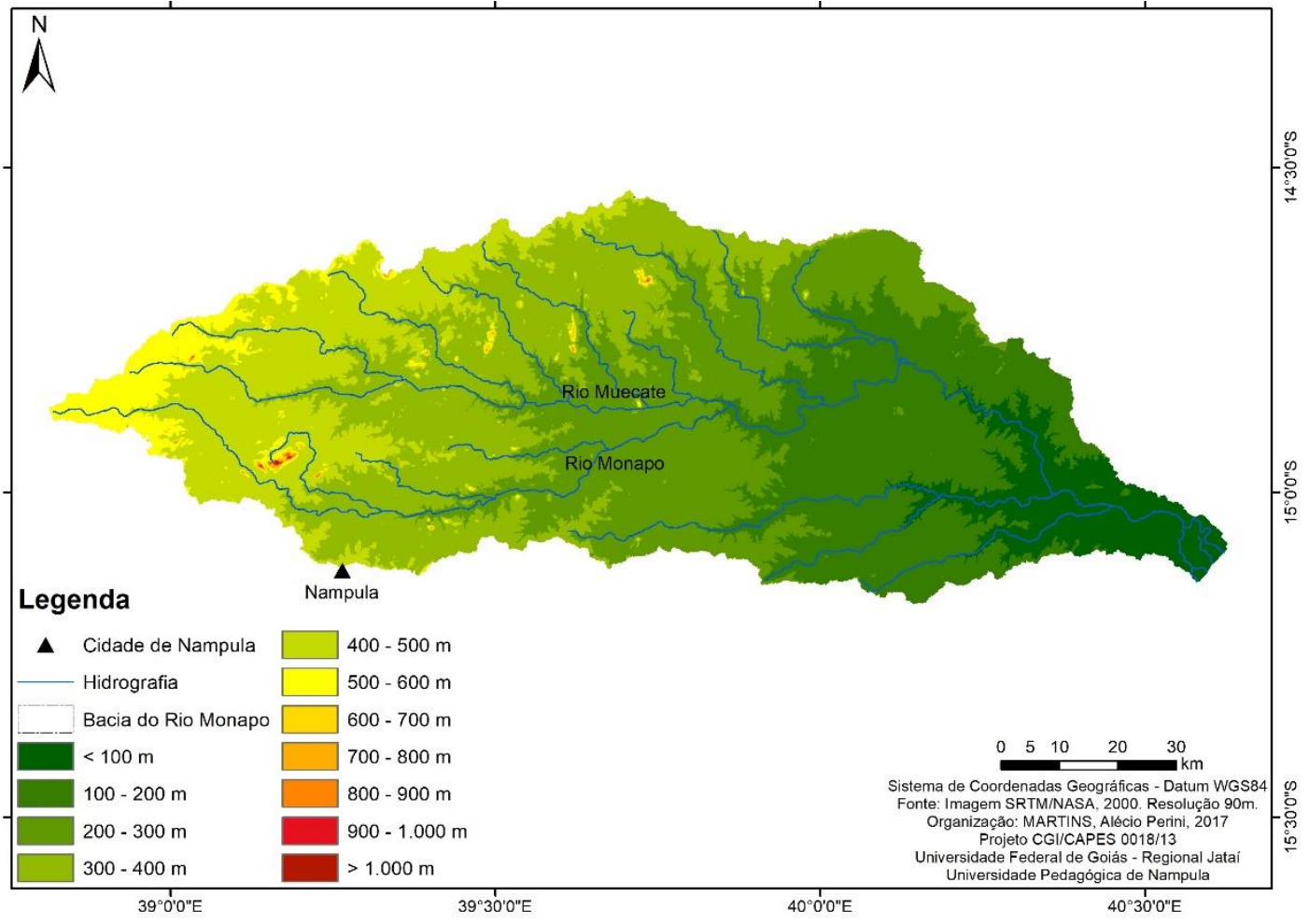

Fonte: EMBRAPA (2012). Organização dos Autores (2017) 
As áreas mais elevadas encontram-se no distrito de Nampula, próximas às nascentes de um tributário do rio Monapo, fundamental para o armazenamento de água no reservatório da cidade de Nampula e nas proximidades do rio Messica, importante curso d'água utilizado para irrigação de lavouras de banana entre os distritos de Muecate e Monapo. Entre as cotas de $200 \mathrm{~m}$ e o oceano Índico, a paisagem é caracterizada por extensas planícies.

Na Figura 10 apresenta-se o um perfil topográfico traçado entre o delta do Rio Monapo e o ponto mais distante a este (nascente principal), onde, com exceção de uma área montanhosa destacada no perfil do alto curso (bloco de granito com altitude superior a $900 \mathrm{~m}$ ), observa-se um relevo com inclinações suaves e altitudes diminuindo gradativamente em direção ao Oceano Índico (transição planalto/planície). Apesar da grande quantidade de canais de drenagem, em campo (novembro de 2016) foi raro observar cursos d'água perenes, exceto pela confluência de grandes canais de drenagem demonstrados nos perfis. Fica nítida a característica de planaltos da região, com destaque para a transição pra planície costeira demonstrada no baixo curso, na altura da marca de $180 \mathrm{~km}$ antes da confluência do rio Monapo com o rio Ampoense. Destaca-se uma área plana de aproximadamente $30 \mathrm{~km}$ de extensão com altitudes inferiores a $50 \mathrm{~m}$ e um delta de aproximadamente $8 \mathrm{~km}$ de extensão.

\section{Figura 10 - Perfil topográfico entre a nascente e o delta do Rio Monapo}

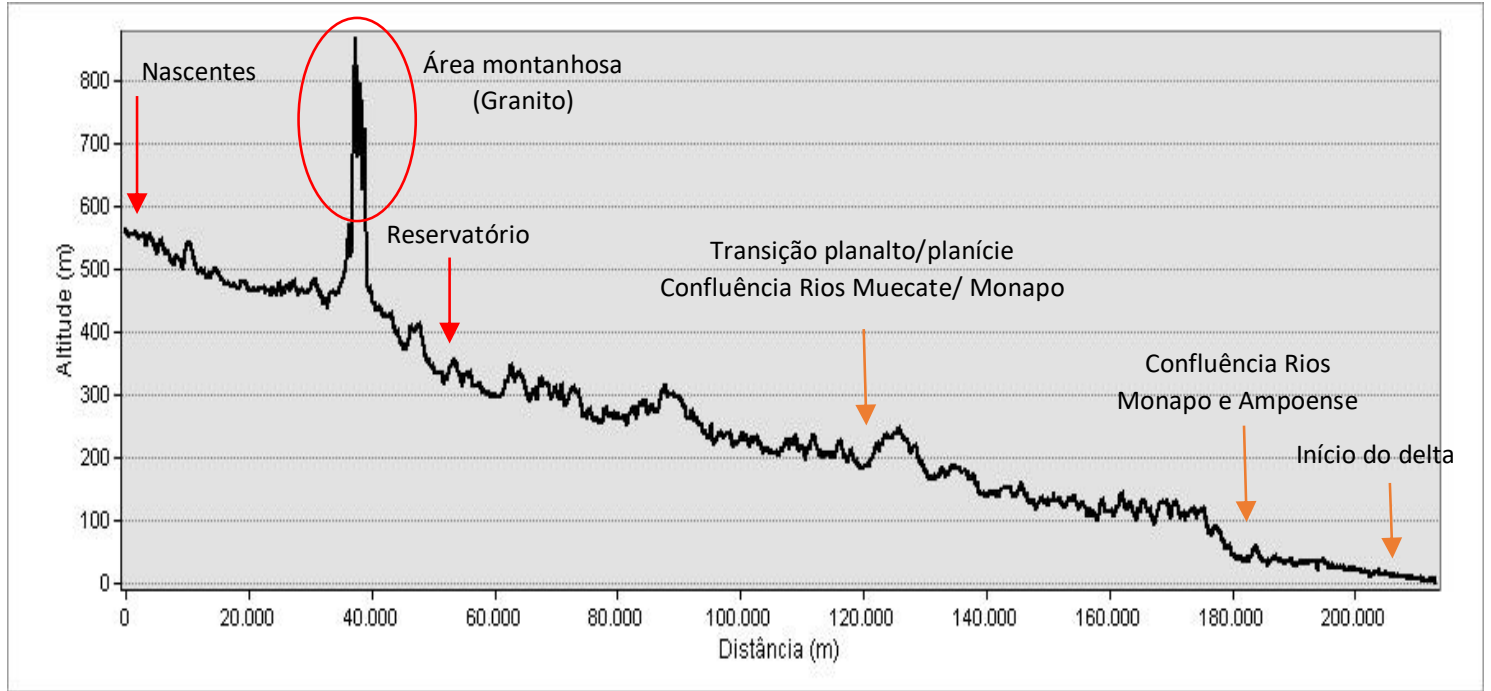

Fonte: Organização dos autores (2017)

Com relação ao regime pluviométrico (Figura 11), este apresenta características semelhantes ao das regiões de transição entre o Cerrado e a Caatinga no Brasil, com volumes abaixo de 800 mm 
no litoral, estando a região fora das áreas de monções do oceano, e próximos a 1200 mm nas proximidades da cidade de Nampula e no alto curso do rio Monapo, onde encontra-se o reservatório de abastecimento da maior parte da população da província.

De acordo com Ussivane (2018), no norte de Moçambique o clima é classificado como Tropical Úmido, com temperaturas médias anuais entre $24^{\circ} \mathrm{C}$ e $26^{\circ} \mathrm{C}$ com estação chuvosa quente mais longa que a seca (Províncias de Niassa e Cabo Delgado), sendo os maiores volumes de chuvas registrados sobre áreas montanhosas. Já nas áreas drenadas pelo rio Monapo, observa-se o Clima Tropical Seco, com período de estiagem com duração superior ao período chuvoso, sendo que o volume entre $800 \mathrm{~mm}$ e $1000 \mathrm{~mm}$ concentra-se entre os meses de novembro e março e as temperaturas médias são superiores a $26^{\circ} \mathrm{C}$.

Figura 11 - Precipitações na Bacia do Rio Monapo - Província de Nampula - Moçambique

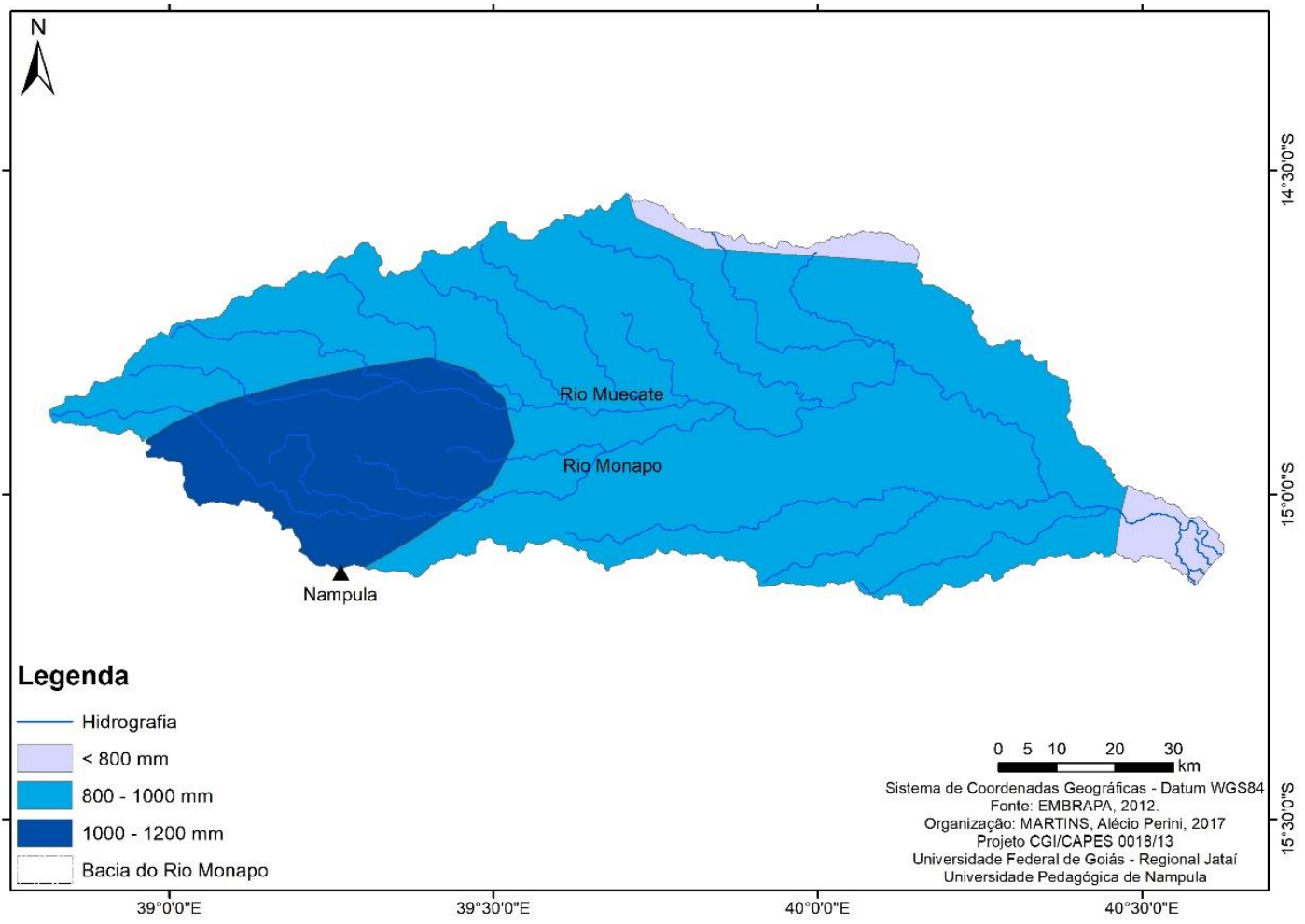

Fonte: EMBRAPA (2012). Organização dos Autores (2017)

Em conversas com moradores locais, foi identificada uma mudança recente na concentração das chuvas, que tem iniciado mais tardiamente, no mês de dezembro, embora não seja possível comprovar estas alterações pela falta de séries de dados pluviométricos mais consistentes. Essa concentração de chuvas em parte da primavera e no verão é uma das responsáveis pela escassez de água em grande parte do ano. Em atividade de campo realizada na primeira quinzena de novembro de 2016 foram observados cenários de escassez hídrica na maior parte da bacia (Figura 12), sendo 
que as chuvas naquele ano iniciaram apenas na primeira semana de dezembro. Parte dos problemas de escassez hídrica na bacia do rio Monapo pode ser associado à geologia da região formada por rochas ígneas/metamórficas que proporcionam aquíferos fraturados na área de estudo, e pelos solos que apresentam altos teores de areia e silte.

\section{Figura 12 - Leito do Rio Monapo no distrito de Monapo}

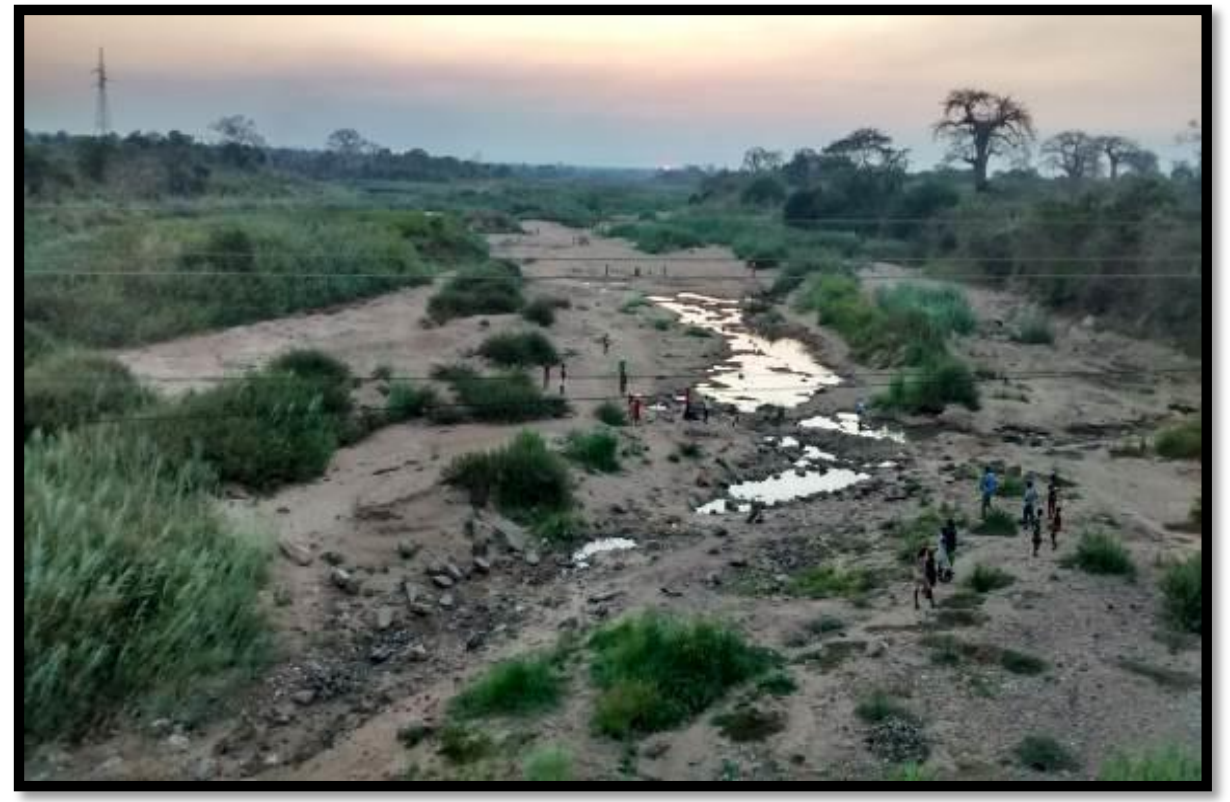

Foto: Dos Autores. (2016)

De acordo com morfometria da bacia, apresentada na tabela 1, com uma área de $8.047 \mathrm{~km}^{2}$, a bacia hidrográfica do rio Monapo apresenta-se como uma das principais redes de drenagem do norte de Moçambique, com perímetro de 630,6 km e 457 canais de primeira ordem, sendo a grande maioria de regime intermitente. Apresenta alto grau de ramificação de seus canais, geometria característica de terrenos cristalinos, sendo classificada como de $5^{\text {a }}$ ordem.

O comprimento axial (distância entre a foz e o ponto mais distante no divisor de águas) é de $198 \mathrm{~km}$, com coeficiente de compacidade de 1,968, fator de forma igual a 0,205 e índice de circularidade de 0,254, indicando formato alongado da bacia e predominância dos processos de escoamento. Estas características conferem à bacia menor probabilidade de ocorrência de chuvas intensas em toda a sua extensão, justificando a baixa susceptibilidade a enchentes (MENEZES et al., 2014) 
Tabela 1 - Características morfométricas da bacia hidrográfica do rio Monapo.

\begin{tabular}{|c|c|c|}
\hline \multicolumn{2}{|c|}{ Características morfométricas } & Resultados \\
\hline \multirow{9}{*}{ Geométricas } & Área (A) & $8.047 \mathrm{~km}^{2}$ \\
\hline & Perímetro $(\mathrm{P})$ & 630,6 km \\
\hline & Número de canais de primeira ordem $(\mathrm{N})$ & 457 \\
\hline & Comprimento Axial (La) & 198 km \\
\hline & Coeficiente de compacidade (Kc) & 1,968 \\
\hline & Fator de forma $(F f)$ & 0,205 \\
\hline & Índice de rugosidade (Ir) & 370,63 \\
\hline & Densidade hidrográfica (Dh) & 0,056 canais $/ \mathrm{km}^{2}$ \\
\hline & Índice de circularidade (Ic) & 0,254 \\
\hline \multirow{7}{*}{ Relevo } & Ponto mais alto da bacia (PI) & $1060 \mathrm{~m}$ \\
\hline & Ponto mais baixo da bacia (PII) & $0 \mathrm{~m}$ \\
\hline & Altitude média & $281,35 \mathrm{~m}$ \\
\hline & Amplitude altimétrica (Hm) & $1060 \mathrm{~m}$ \\
\hline & Declividade do canal principal (S1) & $0,24 \%$ \\
\hline & Índice de Sinuosidade (Is) & $1,22 \mathrm{~km} / \mathrm{km}$ \\
\hline & Razão de relevo (Rr) & $0,004 \mathrm{~m} / \mathrm{m}$ \\
\hline \multirow{7}{*}{ Rede de drenagem } & Comprimento do canal principal (L) & $235 \mathrm{~km}$ \\
\hline & Comprimento total dos canais $(\mathrm{Lt})$ & $2.827 \mathrm{~km}$ \\
\hline & Equivalente vetorial médio em linha reta (Ev) & 191,4 km \\
\hline & Densidade de drenagem (Dd) & $0,351 \mathrm{~km} / \mathrm{km}^{2}$ \\
\hline & Coeficiente de manutenção (Cm) & $2.846,48 \mathrm{~m}^{2} / \mathrm{m}$ \\
\hline & Extensão do percurso superficial (Eps) & $1,423 \mathrm{~km}$ \\
\hline & Ordem da bacia & 5 \\
\hline
\end{tabular}

Fonte: Organização dos Autores (2016)

Ainda com relação à geometria da bacia do Rio Monapo, foi identificada uma densidade hidrográfica de 0,056 canais $/ \mathrm{km}^{2}$, ou seja, existe 1 canal de drenagem para aproximadamente $18 \mathrm{~km}^{2}$, sendo considerada como de baixa densidade. De acordo com Christofoletti (1980), a densidade hidrográfica traduz a capacidade da rede de drenagem em gerar novos cursos d'água em função de suas características fisiográficas, indicando que na bacia do Rio Monapo a água precipitada sobre a superfície leva um tempo maior até encontrar um canal de escoamento, favorecendo outros processos como a infiltração ou a exposição do solo a processos erosivos em áreas que apresentam susceptibilidade para tal.

Conforme Lana et al. (2001), se a densidade hidrográfica for maior que 2 canais $/ \mathrm{km}^{2}$ a bacia apresenta potencial para geração de novos cursos d'água. Isso reforça a afirmação de que a bacia hidrográfica do rio Monapo drena terrenos muito antigos, com atividade morfogenética baixa ou ausente, confirmada pelos valores encontrados para as características morfométricas relativas ao relevo. $O$ índice de rugosidade da bacia é de 370,63, valor considerado forte (SOUZA e RODRIGUES, 2012) em decorrência da amplitude altimétrica da bacia. Este índice determina o risco de degradação da bacia, mas pode ser considerado alto apenas em vertentes mais íngremes, já que na bacia predomina o relevo plano/suave ondulado.

Entre as características morfométricas relacionadas ao relevo, destaca-se a amplitude altimétrica (diferença entre o ponto mais alto e o mais baixo da bacia) de $1060 \mathrm{~m}$. Este valor justificase pela ocorrência de blocos graníticos com altitude superior a $1000 \mathrm{~m}$ no alto curso da bacia, mas a predominância de planaltos e planícies conferem à área uma altitude média de $281,35 \mathrm{~m}$. A declividade do canal principal (entre a nascente e o delta) é considerada baixa $(0,24 \%)$, sendo o relevo 
favorável à conservação da bacia e à proteção da rede de drenagem quanto ao processo de assoreamento (ALVES et al., 2016).

O índice de sinuosidade é uma variável que indica o quanto um canal de drenagem é sinuoso, permitindo inferir que quanto maior a sinuosidade do rio, menor a velocidade de escoamento (SANTOS, 2012). De acordo com Lana et al. (2001) valores próximos a 1 indicam tendência retilínea do canal, enquanto os valores superiores a 2 indicam canais tortuosos e valores intermediários indicam formas transicionais (regulares/irregulares). Para a bacia do Rio Monapo obteve-se um valor de $1,22 \mathrm{~km} / \mathrm{km}$, considerado como transicional mas aproximado a formas retilíneas. Quando observada a razão de relevo muito baixa apresentada pela bacia $(0,004 \mathrm{~m} / \mathrm{m})$, infere-se uma velocidade de escoamento muito baixa e, portanto, o predomínio de processos de infiltração e baixa susceptibilidade à erosão.

O terceiro grupo de variáveis morfométricas corresponde às características da rede de drenagem, sendo o Rio Monapo um canal de $5^{\mathrm{a}}$ ordem conforme a classificação de Strahler (1952). Foram identificados 457 canais de primeira ordem, sendo que o curso principal percorre $235 \mathrm{~km}$ entre a nascente e a foz. As três principais variáveis calculadas neste grupo correspondem à densidade de drenagem $\left(0,351 \mathrm{~km} / \mathrm{km}^{2}\right)$, ao coeficiente de manutenção $\left(2.846,48 \mathrm{~m}^{2} / \mathrm{m}\right)$ e à extensão do percurso superficial $(1,423 \mathrm{~km})$.

A Densidade de drenagem é considerada uma das mais importantes variáveis da análise morfométrica e indica o grau de dissecação topográfica, a quantidade de canais disponíveis para o escoamento e o controle exercido pelas estruturas geológicas (CHRISTOFOLETTI, 1980). Na bacia do Rio Monapo, a densidade de drenagem de 0,351 km/km² é considerada baixa (BELTRAME, 1994), confirmando a baixa dissecação do relevo, a permeabilidade dos solos e as características semiáridas do clima.

Já o coeficiente de manutenção, que indica a quantidade de drenagem necessária para manter um metro de canal de escoamento perene, foi de 2.846,48 $\mathrm{m}^{2} / \mathrm{m}$, ou seja, são necessários 2.846,33 $\mathrm{m}^{2}$ de área para manter um metro de canal perene (ALVES et al., 2016), valor considerado muito alto e que ajuda a explicar a grande quantidade de canais intermitentes na bacia hidrográfica do rio Monapo. A extensão do percurso superficial, que corresponde à distância do escoamento da enxurrada, é de 1,423 km, indicando que os solos apresentam boa permeabilidade.

Os resultados do mapeamento e da análise morfométrica demonstram que a bacia se encontra em condições de relevo bastante retrabalhado, com predomínio de superfícies planas/suave onduladas e apresenta grande potencial de preservação dos recursos naturais, com baixa ou nenhuma susceptibilidade a erosão e a inundações. Os valores encontrados indicam que a bacia apresenta uma maior tendência de infiltração da água no solo, o que favorece a manutenção da água na bacia. Estas informações confirmam que a baixa disponibilidade hídrica está mais relacionada ao baixo índice pluviométrico e à presença de solos arenosos que favorecem a infiltração.

Em campo, constatou-se que as atividades antrópicas contribuem com o agravamento da escassez hídrica. Quando se observa as características de uso e ocupação das terras (Figura 13), a questão da disponibilidade hídrica fica clara considerando as poucas áreas de agricultura, sobretudo no médio e baixo curso, onde os volumes de precipitação são menores. Na Figura 14 é possível observar algumas características de ocupação das terras na bacia do Rio Monapo.

Os campos cultivados ocupavam $1.471 \mathrm{~km}^{2}$, aproximadamente $18,3 \%$ da área da bacia na ocasião do mapeamento realizado pela EMBRAPA (2012), representados por cultivo de frutas como banana, caju e manga, além de cultivos de milho, mandioca, arroz e sisal. Os cultivos também são realizados de forma itinerante em 392,4 km², associados a áreas de savanas no alto curso do Rio 
Monapo. Os campos cultivados e áreas de agricultura itinerante encontram-se associados a criação de rebanhos, principalmente caprinos.

O maior percentual de área $\left(43,7 \%\right.$ do total, que corresponde a $\left.3.515 \mathrm{~km}^{2}\right)$ encontrava-se recoberto por cultivos arbóreos associados a plantações florestais, sendo mais representativos os cultivos de caju e manga utilizados pela população local em sua alimentação diária e comércio nas cidades e nas margens da rodovia que dá acesso à llha de Moçambique.

Figura 13 - Uso e cobertura da terra na Bacia do Rio Monapo

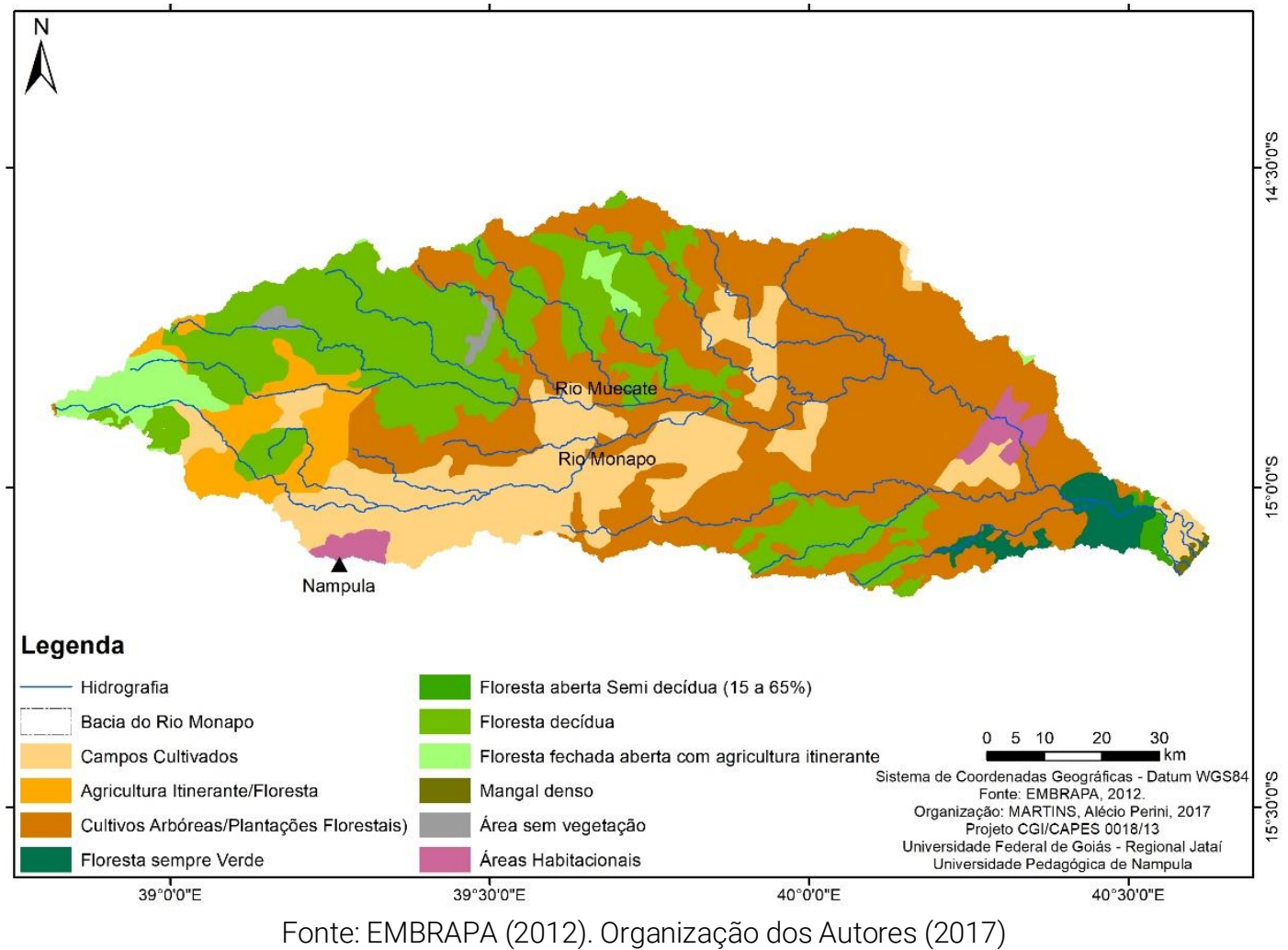

As áreas habitacionais ocupam 144,7 km² (1,8\% da bacia), sendo que a Cidade de Nampula se encontra parcialmente dentro da área por se localizar em uma área de topo, no divisor de águas. Observa-se, ainda, uma área de 44,22 km² sem vegetação, representada por bancos de areia, delta e pequenas áreas desmatadas ou com exposição de rochas.

$\mathrm{Na}$ bacia as formações florestais ocupam aproximadamente 31\% da área, percentual semelhante ao observado em muitas bacias hidrográficas do Cerrado brasileiro, subdividas em: a) Floresta sempre Verde $\left(177,8 \mathrm{~km}^{2}\right)$, no baixo curso do rio Monapo próximo à planície costeira, ocupando 2,2\% da área da bacia; b) Floresta aberta semi decídua $\left(34,8 \mathrm{~km}^{2}\right)$ em continuidade às áreas de floresta sempre verde com área correspondente a 0,4\% da área; c) Floresta decídua, sendo a formação mais comum (2013 km²), correspondendo a 25\% da bacia, com fisionomias savânicas semelhantes aos Cerrados do Brasil (Cerrado stricto sensu); d) Floresta fechada aberta com agricultura itinerante $\left(238,8 \mathrm{~km}^{2}\right)$, correspondente a clareiras abertas em áreas de savana para práticas agrícolas itinerantes ( $3 \%$ da área); e) Mangal denso $\left(13,8 \mathrm{~km}^{2}\right)$, restritos às áreas de mangue 
no delta do Rio Monapo (0,2\% da bacia). Salienta-se que esta é a nomenclatura local adotada pela EMBRAPA (2012) no processo de mapeamento.

Figura 14 - Categorias de uso e cobertura da terra observadas em campo na bacia hidrográfica do rio Monapo - Província de Nampula - Moçambique
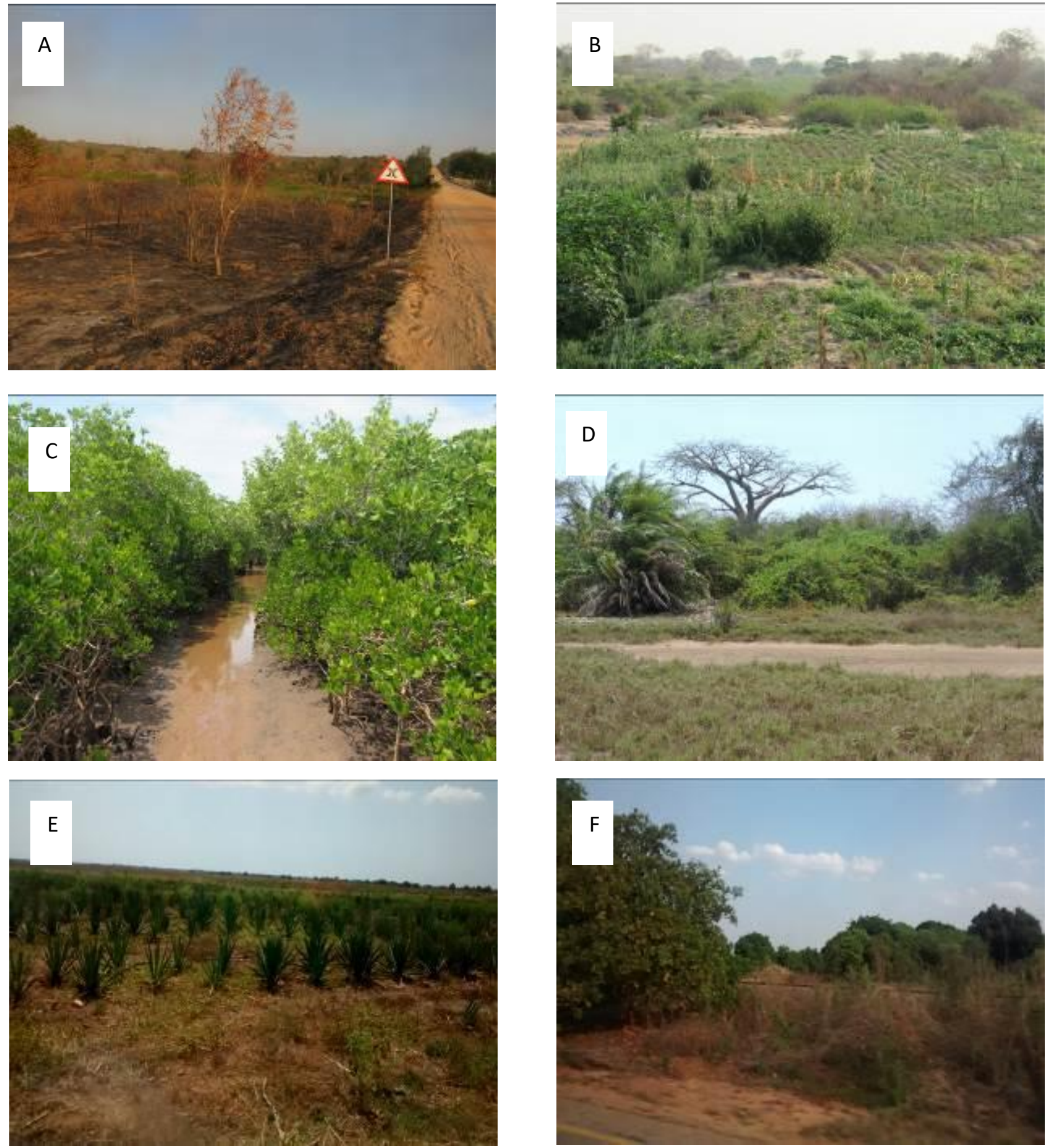

A) Área queimada no alto curso da bacia para prática de agricultura itinerante; B) Campo cultivado às margens do leito seco do rio Monapo ; C) Mangue no delta do rio Monapo; D) Floresta decídua (savana) - em destaque o Baobá; E) Campo cultivado com sisal, nas proximidades do delta do rio Monapo; F) Cultivos arbóreos, com destaque para a produção de caju e manga nas proximidades da ferrovia da Vale do Rio Doce. 


\section{Considerações finais}

Considera-se que os problemas de abastecimento de água na cidade de Nampula, assim como nas demais cidades, vilas e aldeias devem-se mais às características pluviométricas, sobretudo a concentração das precipitações de novembro a março e ao modelo de uso da terra do que às características morfométricas da bacia. É necessário que sejam adotadas medidas que favoreçam o armazenamento e a concentração de água em reservatórios artificiais, criando um sistema de regularização da drenagem aproveitando as águas precipitadas durante o verão. Também se fazem urgentes a elaboração de planos de gestão da bacia visando ordenar o uso e ocupação da terra, como criação de comitê de bacia e elaboração de um Zoneamento Ecológico-Econômico (ZEE).

É necessário criar programas para conservação dos remanescentes florestais, sobretudo nas áreas de nascentes e margens dos cursos d'água, além de integrar a comunidade extrativista às estratégias de conservação dos recursos naturais. Sugere-se a criação de reservas ecológicas ou reservas extrativistas no alto curso do Rio Monapo, visando garantir o abastecimento de água à cidade de Nampula e nas nascentes dos principais tributários da bacia, além da criação de projetos para conservação do delta e das áreas de manguezais.

Assim, torna-se urgente estabelecer planos e estratégias de desenvolvimento sustentável, integrando poder público, universidade e as diversas comunidades que habitam a província, aproveitando todo o potencial ecológico para aumentar a produção de água e viabilizar o abastecimento humano e a produção agropecuária.

\section{Agradecimentos}

Agradecemos à Coordenação de Aperfeiçoamento de Pessoal de Nível Superior (CAPES) por meio do Programa de Mobilidade da Associação das Universidades de Língua Portuguesa (AULP) projeto "Análise geoambiental do impacto da ação antrópica em bacias hidrográficas - integração ensino, pesquisa e extensão na construção de saberes entre Brasil e Moçambique, Processo N023038.005621/2013-8. Agradecemos à direção da Delegação Nampula da Universidade Pedagógica de Moçambique (atual Universidade Rovuma) pela viabilização das atividades de campo, em especial aos professores e professoras dos cursos de Geografia, Gestão Ambiental e Desenvolvimento Comunitário (GADEC) e Geologia. Agradecemos também à EMBRAPA Monitoramento por Satélite pela disponibilização de bases cartográficas e informações socioambientais. 


\section{Referências}

ALVES, W. S. et. al. (2016) Análise morfométrica da bacia do Ribeirão das Abóboras - Rio Verde (GO). Geociências, v.35, n.04, p.652-667.

BATA, E. J. (2014) A vulnerabilidade socioambiental nas áreas de exploração das pedras preciosas e semipreciosas nas aldeias de Nanhupo e Nséue, em Namanhumbir, Distrito de Montepuez (Moçambique), no período de 2004 a 2011. 170f. Dissertação (Mestrado em Geografia) - Programa de Pós-Graduação em Geografia, Universidade Federal de Goiás - Regional Jataí, Jataí.

BELTRAME, A. V. (1994) Diagnóstico do meio ambiente físico de bacias hidrográficas: modelo de aplicação. Florianópolis: UFSC. 112 p.

BERTALANFY, L. von. (1973) Teoria geral dos sistemas. Petrópolis:Vozes.

BERTRAND, G. (1972) Paisagem e geografia física global: esboço metodológico. São Paulo: IGEOG/USP. 27p. (Ciências da Terra, n.13)

BOTELHO, R. M. (1999) Planejamento ambiental em microbacia hidrográfica. In: GUERRA, A. J. T.; SILVA, A. S. J. BOTELHO, R. G. M. (org). Erosão e conservação dos solos: conceitos, temas e aplicações. Rio de Janeiro: Bertrand Brasil. 269-300.

CLARKE, R.; KING, J. (2005) O atlas da água: o mapeamento completo do recurso mais precioso do planeta. São Paulo: Publifolha. 128p.

CHRISTOFOLETTI, A. (1980) A Análise de Bacias Hidrográficas. Geomorfologia. 2. ed. São Paulo: Edgard Blucher Ltda. 102-121p.

EMBRAPA - EMPRESA BRASILEIRA DE PESQUISA AGROPECUÁRIA (2010). Solos e potencialidades agrícolas em Moçambique: o caso da região do corredor de Nacala. Disponível em: https://www.researchgate.net/publication/281440286_SOLOS_E_POTENCIALIDADES_AGRICOLAS_ EM_MOCAMBIQUE_O_CASO_DA_REGIAO_DO_CORREDOR_DE_NACALA Acesso em 04 jan. 2019.

EMBRAPA - EMPRESA BRASILEIRA DE PESQUISA AGROPECUÁRIA (2012). WebGIS Moçambique. Disponível em: http//mapas.cnpm.embrapa.br/mocambique/mapa.html. Acesso em 14 fev. 2017. ESRI - Environmental Systems Research Institute Inc. (2012) ArcGis versão 10.1. EUA: Environmental Systems Research Institute.

FRAGA, M. S. et. al. (2014) Caracterização morfométrica da bacia hidrográfica do Rio Catolé Grande, Bahia, Brasil. Nativa, v. 2, n. 4, p. 214-218.

FREI, V. V. M. (2013) A produção de caju e a dinâmica socioespacial no distrito de Angoche, Nampula - Moçambique. 208f. Dissertação (Mestrado em Geografia) - Programa de Pós-Graduação em Geografia, Universidade Federal de Goiás - Regional Jataí, Jataí.

HORTON, R. E. (1945) Erosinal development of streams and their drainage basin: hydrophysical approach to quantitative morphology. Geological Society of America Bulletin, v. 56, n. 3, p. 275. Disponível em: http://www.geos.ed.ac.uk/homes/s0451705/horton_1945.pdf. Acesso em: 06 dez. 2018.

INE - INSTITUTO NACIONAL DE ESTATÍSTICA DE MOÇAMBIQUE. Disponível em: http://www.ine.gov.mz/. Acesso em 05 nov. 2016.

JORNAL GRATUITO VERDADE. (2015) Jornal gratuito verdade De Moçambique. Escrito por redação em 17 de Fevereiro de 2015. Disponivel em: http://Www.Verdade.Co.Mz/Opiniao/Xiconho ca/61194Xiconhoquices-Da-SemanaconflitoAmurane-E-Mdm-Naufragio-No-Rio-ChipacaBombeirosForneceram-Agua-Casa-De-JorgeKhalau. Acesso em 05 nov. 2017. 
LANA, C. L. et. al.. (2001)Análise morfométrica da bacia do rio Tanque, MG, Brasil. Escola de Minas, v. 54, n. 2, p.121-126.

LOPES, R. M. et. al. (2009) Caracterização fisiográfica e morfométrica da microbacia do córrego Jataí no município de Jataí (GO). Geoambiente, Jataí, GO, n. 9, 142 - 163.

LORENZON, A. S. et. al. (2014) Influência das características morfométricas da bacia hidrográfica do rio Benevente nas enchentes no município de Alfredo Chaves-ES. Ambiente \& Água, v. 10 n. 1, p. 1952006.

MELTON, M. A. (1957) An analysis of the relations among el-ements of climate, surface properties, and geomorphology. New York (Estados Unidos da América): Columbia University.

MENEZES, J. P. C et al. (2014) Morfometria e evolução do uso do solo e da vazão de máxima em uma microbacia urbana. Revista Brasileira de Geomorfologia, Uberlândia, v. 15, n. 4, p. 659-672, out./dez. Disponível em: http://dx.doi.org/10.20502/rbg.v15i4.597. Acesso em 04 jan. 2019.

NARDINI, R. C. et. al. (2013) Análise morfométrica e simulação das áreas de preservação permanente de uma microbacia hidrográfica. Irriga, v. 18, n. 4, p. 687-699.

PORTAL DO GOVERNO DE MOÇAMBIQUE. Disponível em: https://www.portaldogoverno.gov.mz/por/Governo. Acesso em 05 nov. 2016.

SANTOS, A. M. et al. (2012) Análise morfométrica das sub-bacias hidrográficas Perdizes e Fojo no município de Campos do Jordão, SP, Brasil. Ambiente \& Água, Taubaté, v. 7, n. 3, p. 195-211.

SCHUMM, S. A. (1963) A tentative classification of alluvial river channels. United States Geological Survey, Washington (Estados Unidos da América), circular n. 477.

SCHUMM, S. A. (1956) Evolution of drainage systems and slopes in badlands at Perth Amboy, New Jersey. Geological Society of America Bulletin, Washington (Estados Unidos da América), v. 67, n. 5, p. 597- 646, may. Disponível em: http://dx.doi.org/10.1130/0016-7606(1956)67[597:EODSAS]2.0.C0;2. Acesso em 04 jan. 2019.

SERTOLI, P. E. (2009) As características do complexo de troca e a classificação dos solos da República de Angola. 105f. Dissertação (Mestrado em Engenharia Agronómica) - Instituto Superior de Agronomia, Universidade Técnica de Lisboa. Lisboa.

TRATA BRASIL. (2018) Perdas de água 2018 (SNIS 2016): Desafios para a disponibilidade hídrica e avanço da eficiência do Saneamento Básico. Disponível em: http://www.tratabrasil.org.br/images/estudos/itb/perdas-2018/estudo-completo.pdf Acesso em 04 jan. 2019.

SOUSA, F. A.; RODRIGUES, S. C. (2012) Aspectos morfométricos como subsídio ao estudo da condutividade hidráulica e suscetibilidade erosiva dos solos. Mercator, Fortaleza, v. 11, n. 25, p. 141-151, mai./ago. Disponível em: http://dx.doi.org/10.4215/rm.v11i25.699. Acesso em 04 jan. 2019. STRAHLER, A. N. (1952) Hypsometric (area-altitude) analysis and erosional topography. Geological Society of America Bulletin, v. 63, p.1117-1142.

UNITED STATES GEOLOGICAL SURVEY (USGS). Downloads de imagens Landsat, SRTM e Sentinel. Disponível em: https://earthexplorer.usgs.gov/ Acesso em: 20 set. 2016.

USSIVANE, M. S. (2018) Clima ou climatologia de Moçambique (Tipos, Factores, Características, Localização). Disponível em: https://www.escolademoz.com/2018/03/clima-ou-climatologia-democambique_28.html Acesso em 04 jan. 2019.

VILLELA, S. M; MATTOS, A. (1975) Hidrologia aplicada. São Paulo: McGraw-Hill do Brasil. 